\title{
Es git e Bueb mit Name Fritz
}

\author{
Es git e Bueb mit Name Fritz \\ Es git e Bueb mit Name Fritz \\ Und dä cha renne wi dr Blitz \\ Und dä cha renne wi dr Blitz \\ Är rennt, dä unerhört Athlet \\ Är rennt, dä unerhört Athlet \\ So schnäll, das me ne gar nid gseht \\ So schnäll, das me ne gar nid gseht \\ Und wil er geng isch grennt bis jitz \\ Und wil er geng isch grennt bis jitz \\ Het ne no niemer gseh, dr Fritz \\ Het ne no niemer gseh, dr Fritz \\ Und ig sogar, drVärslischmid \\ Und ig sogar, drVärslischmid \\ Mues zuegäh:Vilich gits ne nid \\ Mues zuegäh:Vilich gits ne nid
}

Mani Matter, Schweizer Chansonnier, 1936-1972

\section{Lieber Philipp,}

ich weiss, dass auch du dich immer noch gerne an die Hermeneutische Freitagnachmittagssozietät in Zürich erinnerst - in den Zeiten, in denen bei uns noch niemand von credit points sprach und wir einfach frei über die vor uns liegenden Texte diskutierten.Vielleicht erinnerst du dich aber auch noch daran - du, Ingolf und Franziska, ihr wart noch nicht lange an dieser Veranstaltung dabei -, wie Markus Huppenbauer einmal eine Sitzung unterbrach und dir anhand eines Vergleichs von Deutschen und Schweizer Autobahnen einen deutlichen Wink mit dem Zaunpfahl gab (wer es nicht weiss: auf Schweizer Autobahnen gibt es eine Tempolimite).

Der Ordnungsantrag hat gewirkt, jedenfalls bist du für uns in letzten Jahren in Zürich durchaus zu einer sichtbaren Grösse geworden. Und auch wenn das letzte Thema der Hermeneutischen Blätter, für das du als geschäftsführender Oberassistent am IHR Verantwortung zeichnest, eher an deine Zeiten vor dem Hupperbauerschen Ordnungsantrag erinnern, und auch wenn du durch deine neue Stelle in Rostock für uns wieder ein Stück unsichtbarer geworden 
bist - die Spuren, die du hinterlassen hast, bleiben. Hab herzlichen Dank für die so anregende und herausfordernde Zeit zusammen mit dir in Zürich! Und natürlich freuen wir uns, wenn du dich durch Geschriebenes - gerne auch in den Blättern! - und vor allem in persona $\mathrm{ab}$ und $\mathrm{zu}$ wieder sichtbar machst bei uns. Du bist hier immer herzlich willkommen!

Danke und auf Wiedersehen!

Andreas Hunziker 